\title{
Placenta previa rates in relation to prior cesarean section deliveries, A 15-year single-center analysis
}

\author{
Ahmad B. Alwazzan \\ King Abdulaziz University Hospital \\ abdullah Kafy ( $\nabla$ drabdullah.kafy@gmail.com ) \\ King Abdulaziz University Hospital \\ Samera F. AlBasri \\ King Abdulaziz University Hospital \\ Ahmed A. Mousa \\ King Abdulaziz University Hospital \\ Lujain K. Halawani \\ King Abdulaziz University Hospital \\ Ibtisam H. Farran \\ King Abdulaziz University Hospital
}

\section{Research article}

Keywords: Placenta previa, cesarean section delivery, repeat cesarean section

Posted Date: January 2nd, 2020

DOI: https://doi.org/10.21203/rs.2.19936/v1

License: (c) (i) This work is licensed under a Creative Commons Attribution 4.0 International License.

Read Full License 


\section{Abstract}

Background: To estimate the rate of placenta previa in relation to prior delivery via cesarean section (CS) during a 15-year period in an academic medical center, King Abdulaziz University Hospital (KAUH), in Jeddah, Saudi Arabia.

Methods: In this retrospective study, we reviewed the medical records of all pregnant women who delivered at KAUH from January 2001 to December 2015. For each year, the research team recorded the total number of deliveries, as well as the number and percentage of CS deliveries and patients with placenta previa. The association between placenta previa and previous CS was assessed.

Results: Out of the 62,701 deliveries at KAUH during the study period, 13,404 were CS deliveries, producing an overall CS rate of $21.4 \%$. The total number of patients with placenta previa was 260 , for a placenta previa rate of 4.14 cases/1,000 births. Of patients with placenta previa, 135 had a prior CS (60\%), whereas 91 multigravida women had no previous CS (40\%). There is positive correlation between number of CS and number of placenta pravia.

Conclusion: In spite of, significant positive correlation between number of CS and number of placenta previa. The rate of placenta previa was not significantly different between patients with or without prior CS delivery. This suggests that factors other with previous CS could play role in the development of placenta previa especially in primgravida.

\section{Background}

Approximately 1 in 200 to 250 pregnancies are complicated by placenta previa at the time of delivery (1, 2). Placenta previa is characterized by a placenta abnormally implanted in the lower uterine segment so it partially or totally covers the internal cervical os. It is associated with a defect in the decidua basalis. Placenta previa has a major impact on maternal health and well-being, with consequent adverse effects on perinatal morbidity and mortality, which are primarily attributed to preterm birth. The maternal mortality rate of placenta previa is high (up to $7 \%-10 \%$ ), primarily related to hemorrhage and operative injuries (2).

The incidence of placenta previa has increased considerably in recent decades, along with an increasing rate of cesarean section (CS) and other uterine surgery, such as myomectomy and curettage (3). A disrupted uterine cavity secondary to prior surgery is considered a major factor leading to abnormal placentation, including placenta previa. Among all uterine surgeries, the rate of CS delivery has risen substantially over the last couple decades. In addition to a previous CS, other factors reported to be associated with an increased risk of placenta previa include advanced maternal age, grand multi-parity, previous abortion, and smoking during pregnancy (4).

King Abdulaziz University Hospital (KAUH) is a major university hospital, providing tertiary care services for more than $50 \%$ of the community in the south part of Jeddah city, Saudi Arabia. The Department of 
Obstetrics and Gynecology is one of the largest departments at KAUH, where all subspecialties are available to care for a large number of high-risk patients. There are approximately 4,000 deliveries each year at KAUH, with a rising number of CSs, primarily because of repeat CS. In addition to its adverse effects on maternal and neonatal outcomes, the increasing CS rate is now a public health problem because of the economic burden to the country. CS delivery is among the top five surgical procedures and reasons for hospitalization. The objective of the current study was to determine the incidence of placenta previa in relation to prior CS delivery during 15 years at an academic medical center (KAUH) in Saudi Arabia.

\section{Methods}

The protocol for this retrospective study was approved by the research ethical committee of the Faculty of Medicine at King Abdulaziz University (reference number, 733-12). The research team reviewed the medical records of all pregnant women who delivered at KAUH from January 2001 to December 2015. For each year, we collected data regarding the total number of deliveries, the number of CS deliveries, and the number of patients with placenta previa. Placenta previa was diagnosed when the placenta covered the internal cervical os either partially or completely after 28 weeks gestation. The diagnosis of placenta previa was based on ultrasonography and confirmed at the time of cesarean delivery. Gestational age was determined by the last menstrual period and the first-trimester ultrasound.

It is the policy of KAUH to admit all patients diagnosed with placenta previa until the time of delivery by CS (preferably performed at 36 weeks gestation or later). During this period, each woman is evaluated preoperatively by an anesthesiologist and at least 6 units of packed red blood cells are prepared.

\section{Statistical analysis}

The variables for which data were collected include the following: gravidity, parity, prior caesarean section delivery and the gestational age at delivery. The frequency of occurrence for each variable was calculated, and P values less than 0.01 were considered to be significant. The Statistical Package for the Social Sciences (SPSS version 20) used to analyze data using a t-test for different in means and (chisquare test) for the frequency of occurrence of different variables calculated as odd ratio and $5 \%$ Confidence Interval statistically significant when P-Value less than 0.05 .

\section{Results}

Table 1 shows the total number of deliveries, total number of CS deliveries, CS rate, total number of women with placenta previa, and placenta previa rate for each year during the study. Out of the 62,701 deliveries from January 2001 to December 2015, 13,404 were CS deliveries, representing a CS rate of $21.4 \%$. The number of women with placenta previa during this time period was 260 , for an overall placenta previa rate of $0.415 \%$ or 4.15 per 1,000 births. The percentage of women undergoing CS who had placenta previa was $1.9 \%$. 
Of the 260 patients with placenta previa, the youngest was 18 years of age and the oldest was 45 years of age. Thirty-four (13.1\%) were primigravida, and 226 (86.9\%) were multigravida.

Of the 260 women with placenta previa, $125(48 \%)$ had no previous CS delivery, whereas $135(52 \%)$ had a prior CS delivery. These percentages were not significantly different.

As standard of care, all patients with placenta previa were delivered by CS: 144 (55.4\%) as an emergency procedure and $116(44.6 \%)$ as an elective procedure. The majority $(75 \%)$ of these procedures were performed under general anesthesia. Two patients during the study period died in the postpartum period because of massive hemorrhage and subsequent multi-organ failure, resulting in a $0.77 \%$ mortality rate associated with placenta previa.

\section{Discussion}

In modern obstetrics, obstetrical hemorrhage remains a major cause of morbidity and mortality. Abnormal placentation is a prominent source of adverse outcomes in both the mother and the fetus, secondary to the potential for hemorrhage, blood transfusion, preterm delivery, and emergency hysterectomy (5). Strategies to prevent or reduce the incidence of abnormal placentation have been studied, including consideration of the relationship between prior CS and the subsequent development of placenta previa.

In this retrospective study, we reviewed the numbers and rates of placenta previa and cesarean deliveries over the last 15 years to determine temporal trends and the relationship between placenta previa and cesarean deliveries (6). The data showed that the number of deliveries per year was generally stable over time, ranging from 3,200 to 4,700 . By contrast, the number of CS deliveries steadily increased from 560 in 2001 to more than 1,000 in 2015 . There was a corresponding progressive increase in the CS rate from $14 \%$ to $30 \%$. As the total number of deliveries did not increase over the study years, the increase in CS rate was likely attributed to an increasing number of repeat CS deliveries, an increasing rate of maternal requests for CS (especially with the increased rate of pregnancies arising from assisted reproductive technology and the associated increased risk of multiple gestation deliveries), and declining number of trials of labor after CS.

Although the CS rate rose progressively over the study period, the number and percentage of patients with placenta previa did not exhibit a similar trend. The placenta previa rate increased somewhat over time, but the rate did not increase in a clearly progressive pattern. Furthermore, the rate of placenta previa did not differ significantly between patients with or without a previous CS, thereby suggesting that the presence of a uterine scar alone did not affect the incidence of placenta previa.

Our results suggest additional lines of research for future studies. For example, it would be interesting to know whether the risk of placenta previa was affected by specific factors related to the primary CS, such as the timing of or indication for the prior CS. The effect of number of prior CS deliveries (single versus multiple) is another possible area of future study. ${ }^{7}$ Future analyses may include examining placenta 
previa rates while adjusting for these CS-related factors and patient characteristics $(8,9)$. To further understand the development of placenta previa, it would also be interesting to evaluate tissue healing and structural changes after both normal vaginal and CS deliveries.

The maternal mortality rate of $0.77 \%$ in our patients with placenta previa is much lower than the $7 \%$ to $10 \%$ rates reported in the literature, despite $55.4 \%$ of our patients requiring emergency CS. Our low rate may be at least partially attributed to the expertise of care provided at KAUH, as a referral center for highrisk obstetric patients (10). Similar to previous reports, maternal mortality was related to massive hemorrhage and subsequent multi-organ failure $(10,11)$.

\section{Conclusion}

Over the last 15 years, the rate of both placenta previa and CS increased at KAUH, an academic, referral center for high-risk obstetrics. However, the increase in placenta previa was not related to the increase in CS deliveries, indicating the need to evaluate the role of factors other than CS alone in the development of abnormal placentation.

\section{Declarations}

Ethical approval available from ethical committee at king abdullaziz university hospital. The datasets used and analysed during the current study are available from the corresponding author on reasonable request. The authors declare that they have no competing interests. All authors read and approved the final manuscript.

\section{Authors' contributions}

AW, SB and AM design the study, formulation of needed variable and literature review.

AK analyzed the data using SPSS and and interpreted the patient data.

LH \& IF apply for ethical approval and collected date form patient files.

\section{Abbreviations}

CS: cesarean section

KAUH: king abdullaziz university hospital

\section{References}

1. Wu S, Koeherginsky M, Hibbard IU. Abnormal placentation: twenty-year analysis. Am J Obstet Gynecol. 2005;192:1458-61. 
2. Miller DA, Chollet JA, Goodwin TM. Clinical risk factors for placenta previa-placenta accreta. Am J Obstet Gynecol. 1997;177:210-4 .

3. Gielchinsky Y, Rojansky N, Fasouliotis SJ, et al. Placenta accreta: summary of 10 years: a survey of 310 cases. Placenta. 2002;23:210-4.

4. Rao KP, Belogolovkin V, Yaakowitz J, et al. Abnormal placentation: Evidence-based diagnosis and management of placenta previa, placenta accrete, and vasa previa. Obstet Gynecol Surv. 2012;67:503-519.

5. Faiz AS, Ananth CV. Etiology and risk factors for placenta previa: an overview and meta-analysis of observational studies. J Matem Fetal Neonatal Med 2003;13:175-90.

6. Gurol-Urganci I, Cromwell DA, Edozien LC, et al. Risk of placenta previa in second birth after first birth cesarean section: A population-based study and meta-analysis. BMC Pregnancy Childbirth. 2011;11:95.

7. Berube $L$, Arial M, Gagnon $G$, et al. Factors associated with lower uterine segment thickness near term in women with previous caesarean section. J Obstet Gynaecol 2011;33:581-7.

8. Slxilapurkar SL. Increased incidence of placenta praevia and accreta with previous caesareans-a hypothesis for causation. 2013;33(8):806-9.

9. Abuhamad A. Morbidly adherent placenta. Semin Perinatol. 2013;37:359-64.

10. Hayakawa $\mathrm{H}$, Itakura A, Mitsui T, et a1. Methods for niyometrium closure and other factors impacting effects on cesarean section scars of the uterine segment detected by the ultrasonography. Acta Obstet Gynecol Scand. 2006;85:429-34.

11. Solheim KN, Esakoff TF, Little SE, et al. The effect of cesarean delivery rates on the future incidence of placenta previa, placenta accreta, and maternal mortality. J Matem Fetal Neonatal Med 2011;24:1341-6.

\section{Tables}

\section{Table 1: The number of deliveries, cesarean section rates, and placenta previa rates at king Abdulaziz university hospital during the period from 2001 to 2015.}




\begin{tabular}{|c|c|c|c|c|c|c|}
\hline year & $\begin{array}{c}\text { No. of } \\
\text { deliveries }\end{array}$ & $\begin{array}{l}\text { No. of CS } \\
\text { deliveries }\end{array}$ & $\begin{array}{c}\text { CS rate } \\
\text { (\%) }\end{array}$ & $\begin{array}{l}\text { No. of } \\
\text { women with } \\
\text { placenta } \\
\text { previa }\end{array}$ & $\begin{array}{l}\text { Placenta } \\
\text { previa } \\
\text { rate } \\
(\%)\end{array}$ & $P$ value \\
\hline 2001 & 3790 & 560 & 14.8 & 11 & 0.29 & Reference \\
\hline 2002 & 4165 & 726 & 17.4 & 08 & 0.19 & $0.036 *$ \\
\hline 2003 & 4927 & 823 & 16.7 & 08 & 0.16 & $0.031 *$ \\
\hline 2004 & 4717 & 829 & 17.6 & 15 & 0.32 & 0.64 \\
\hline 2005 & 3899 & 692 & 17.8 & 07 & 0.18 & $0.033^{*}$ \\
\hline 2006 & 3834 & 705 & 18.4 & 15 & 0.39 & 0.13 \\
\hline 2007 & 3919 & 813 & 20.8 & 22 & 0.56 & $<0.001 *$ \\
\hline 2008 & 4398 & 929 & 21.1 & 16 & 0.36 & $0.031 *$ \\
\hline 2009 & 4243 & 932 & 21.9 & 17 & 0.40 & 0.101 \\
\hline 2010 & 4238 & 989 & 23.3 & 23 & 0.54 & $<0.001 *$ \\
\hline 2011 & 4760 & 1158 & 24.3 & 31 & 0.65 & $<0.001^{*}$ \\
\hline 2012 & 4599 & 1118 & 24.3 & 30 & 0.65 & $<0.001 *$ \\
\hline 2013 & 4373 & 1138 & 26.0 & 27 & 0.62 & $<0.001 *$ \\
\hline 2014 & 3286 & 930 & 28.3 & 20 & 0.61 & $<0.001 *$ \\
\hline 2015 & 3553 & 1062 & 29.8 & 12 & 0.33 & 0.71 \\
\hline Total & 62,701 & 13,404 & 21.4 & 260 & 0.415 & \\
\hline
\end{tabular}

Abbreviations: CS, cesarean section; No., number

Table (2) Characters of women with placenta previa, King Abdelaziz University hospital during the period from 2001 to 2015. 


\begin{tabular}{|c|c|c|}
\hline Data & Number & percentage \\
\hline $\begin{array}{l}\text { Gravidity } \\
\text { Primigravidity } \\
\text { Multigravdity }\end{array}$ & $\begin{array}{l}34 \\
226\end{array}$ & $\begin{array}{l}(13.1) \\
(86.9)\end{array}$ \\
\hline $\begin{array}{l}\text { History of CS }(n=226) \\
\text { No history CS } \\
\text { History of CS }\end{array}$ & $\begin{array}{l}91 \\
135\end{array}$ & $\begin{array}{l}(40) \\
(60)\end{array}$ \\
\hline $\begin{array}{l}\text { Current method of delivery } \\
\text { Elective CS } \\
\text { Emergency CS }\end{array}$ & $\begin{array}{l}144 \\
116\end{array}$ & $\begin{array}{l}(55.4) \\
(44.6)\end{array}$ \\
\hline $\begin{array}{l}\text { Mortality } \\
\text { No survived } \\
\text { Survived }\end{array}$ & $\begin{array}{l}2 \\
258\end{array}$ & $\begin{array}{l}(0.77) \\
(99.33)\end{array}$ \\
\hline $\begin{array}{l}\text { Age } \\
\text { Mean } \pm \text { SD }(25.43 \pm 10.71) \\
\text { Range }(18-45)\end{array}$ & & \\
\hline
\end{tabular}

\section{Figures}

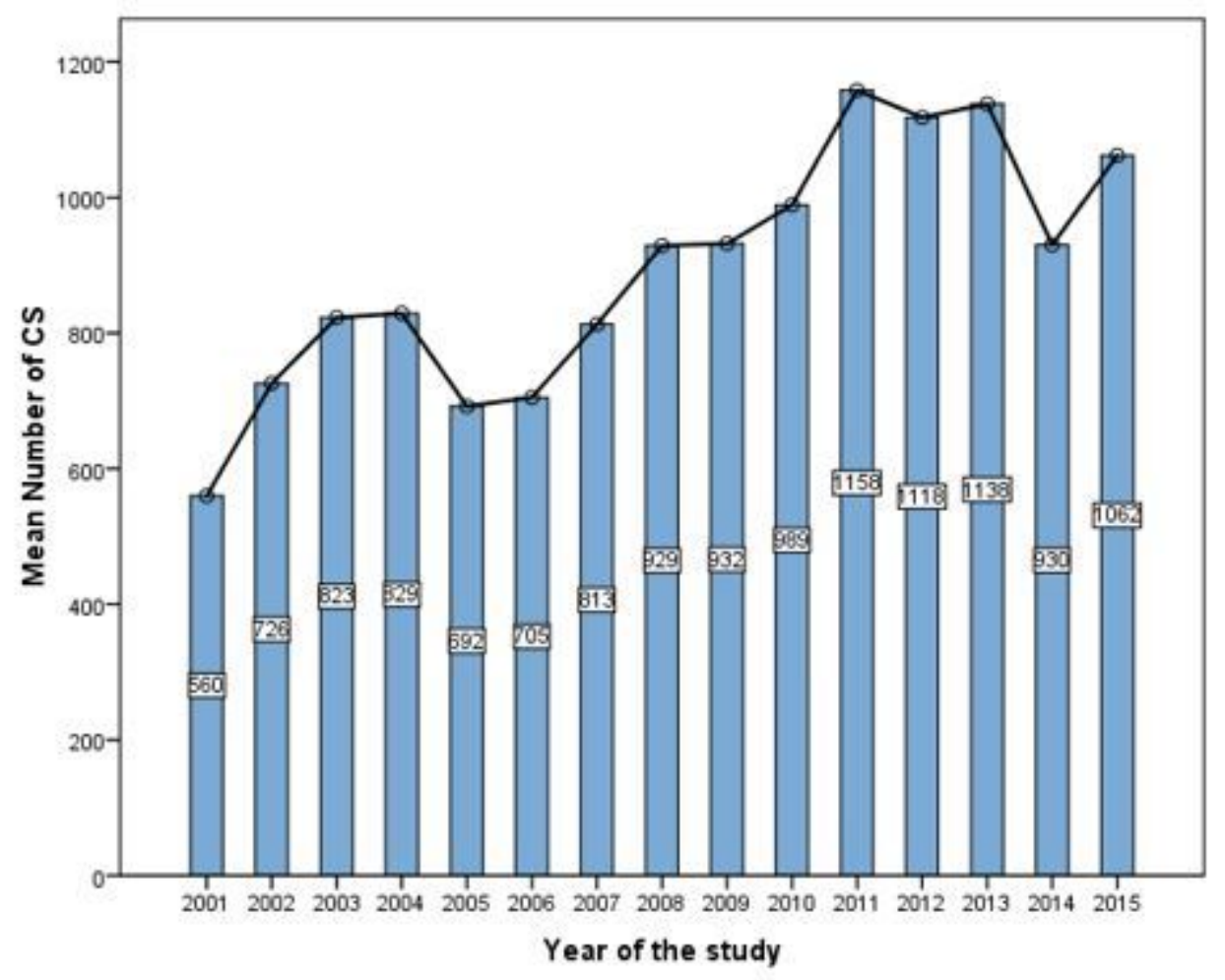

Figure 1

Bar chart and line of trend for Caesarian section during the period from 2001 to 2015. 


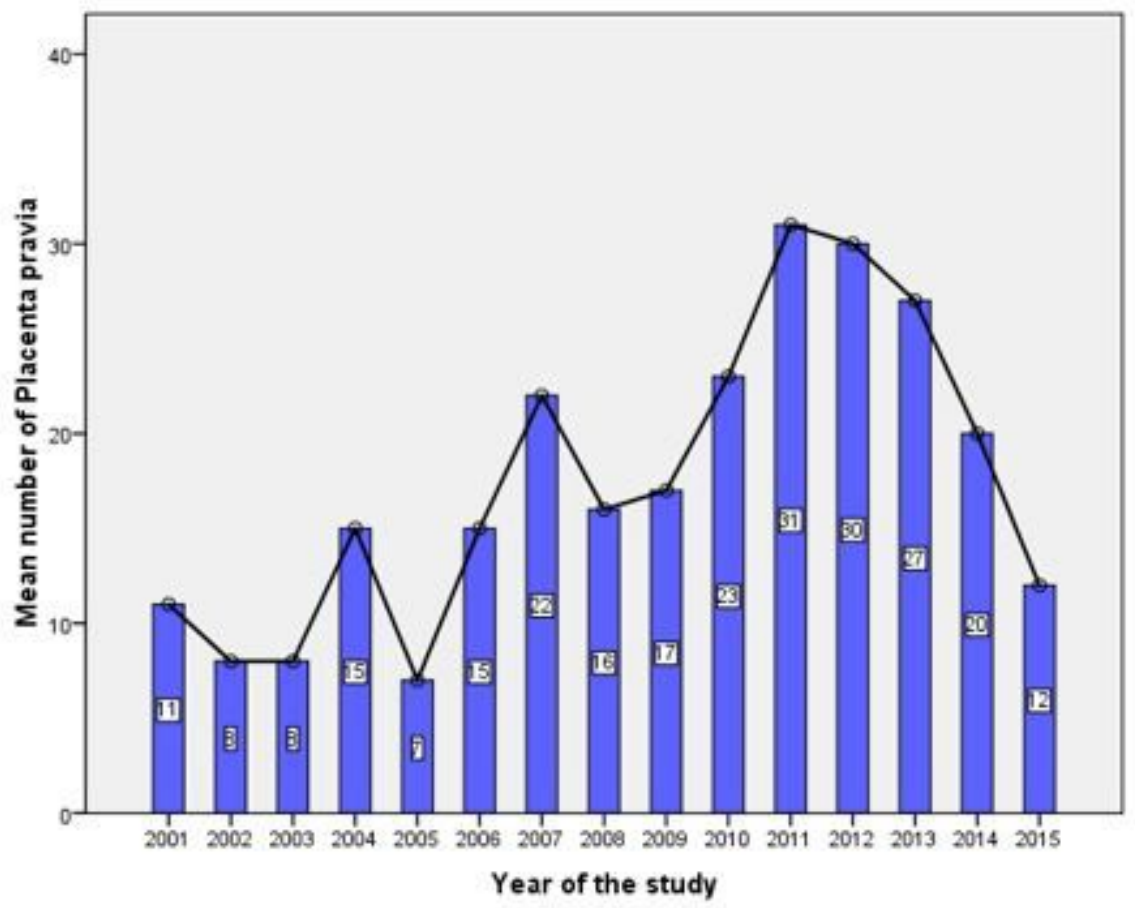

Figure 2

Bar chart and line of trend for number of placenta pravia during the period from 2001 to 2015.

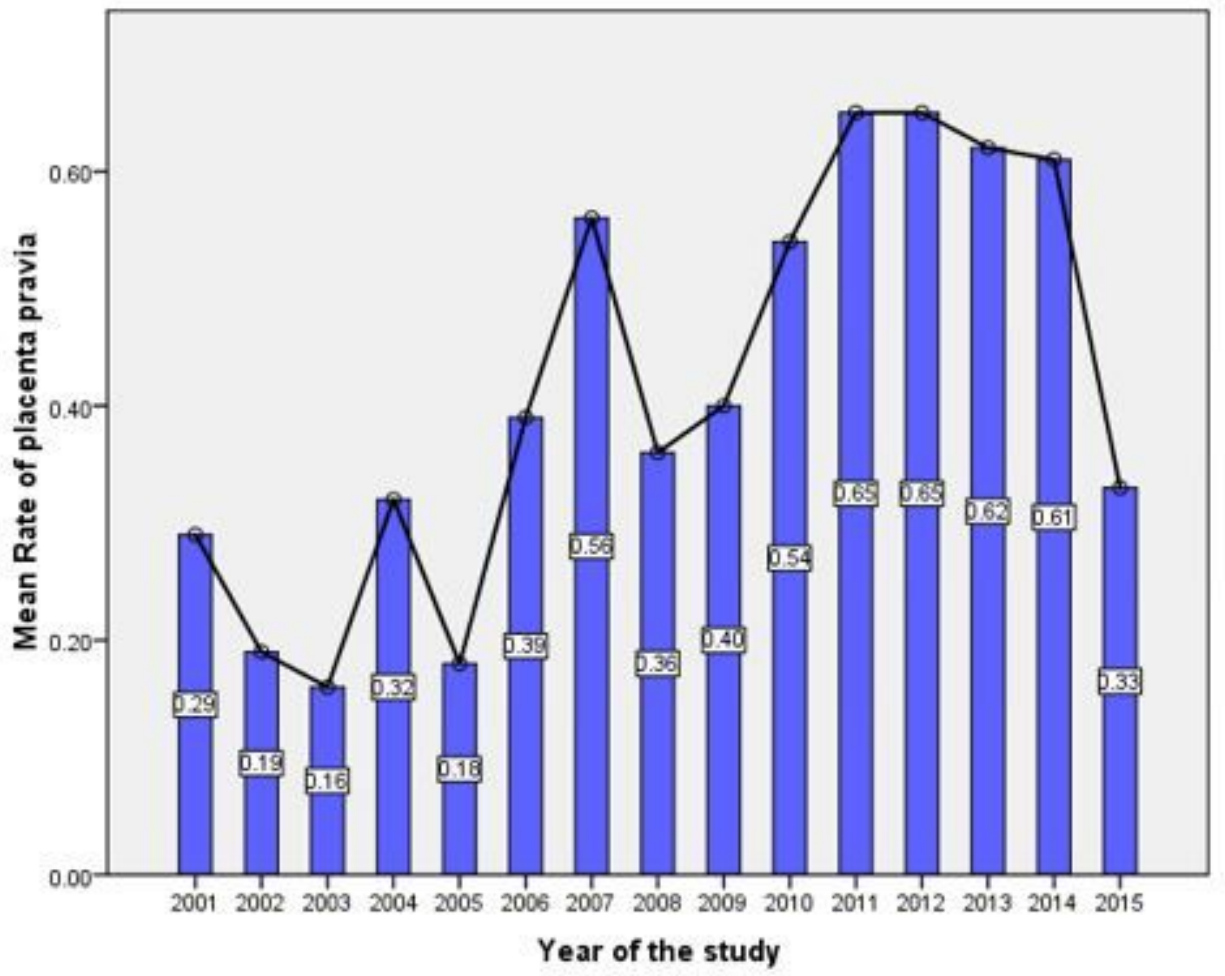

Figure 3 
Bar chart and line of trend for incidence of placenta pravia during the period from 2001 to 2015.

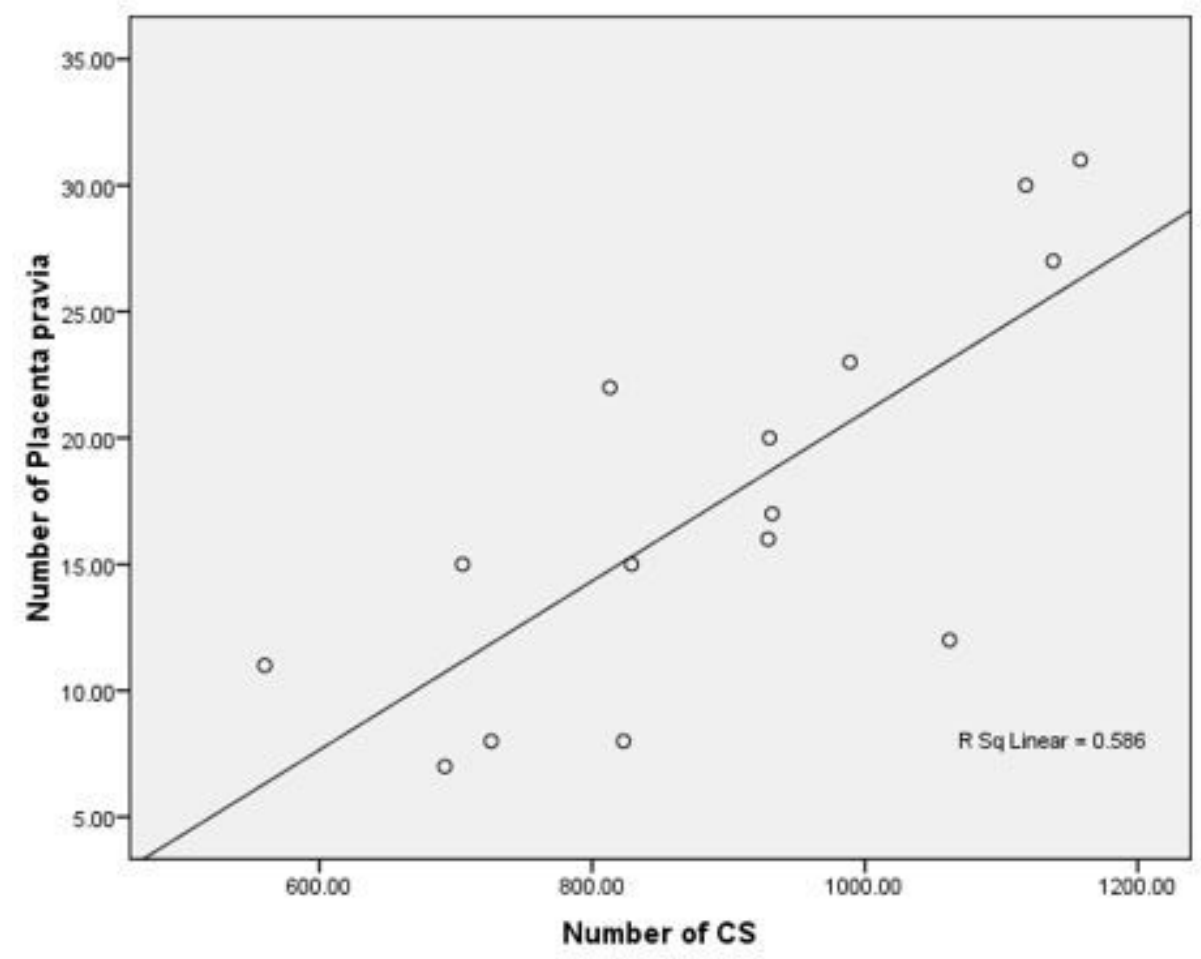

\section{Figure 4}

Pearson Correlation coefficient between number of CS deliveries and placenta pravia. Corre-lation coefficient $r=0.77 p=<0.001$ 